\title{
Aortic root replacement with stentless xenografts in patients with aortic stenosis
}

Valentino Bianco, DO, MPH, ${ }^{\mathrm{a}}$ Arman Kilic, MD, ${ }^{\mathrm{a}, \mathrm{b}}$ Thomas G. Gleason, MD, ${ }^{\mathrm{a}, \mathrm{b}}$ Edgar Aranda-Michel, BS, ${ }^{\mathrm{a}}$ Forozan Navid, MD, ${ }^{\mathrm{a}, \mathrm{b}}$ Suresh Mulukutla, MD, ${ }^{\mathrm{b}}$ and Ibrahim Sultan, MD ${ }^{\mathrm{a}, \mathrm{b}}$

\section{ABSTRACT}

Objective: Stentless bioprosthetic valves such as the Freestyle conduit have been widely used as an option for aortic root replacement in the setting of aortic root aneurysms with acceptable long-term outcomes. However, there is a paucity of data regarding the use of the Freestyle prosthesis in patients with aortic stenosis.

Methods: All patients with a primary diagnosis of severe aortic stenosis who underwent complete aortic root replacement with Freestyle conduits were included. Primary outcomes included survival and readmissions for heart failure. Secondary outcomes included immediate postoperative complications.

Results: In total, 2529 patients with severe aortic stenosis who needed an open aortic valve replacement with a biological prosthesis were operated on between 2011 and 2017. Of these, 294 patients underwent aortic root replacements using the Freestyle conduit with a primary diagnosis of native or prosthetic aortic stenosis. Eighty-four $(28.6 \%)$ of the patients underwent reoperative sternotomy. The majority $(53.7 \%)$ of the cohort were men. The mean age was $67.5 \pm 13.0$ years. Mean Society of Thoracic Surgeons Predicted Risk of Mortality when calculated with the assumption of aortic valve replacement \pm coronary artery bypass grafting was $8.10 \% \pm 10.8$. The median follow-up time for the entire group was 2.7 years (interquartile range 0.9-4.5 years). Operative (30day) mortality was $7.1 \%(\mathrm{n}=21)$. Kaplan-Meier mortality estimates at 1 and 5 years are $16.6 \%$ and $27.6 \%$, respectively. Mean gradients were $7.15 \pm 4.47 \mathrm{~mm} \mathrm{Hg}$ at 1 month and $6.32 \pm 4.76 \mathrm{~mm} \mathrm{Hg}$ at 1 year. Readmissions for heart failure at 30 days, 1 year, and 5 years were $5.6 \%, 11.8 \%$, and $17.4 \%$, respectively.

Conclusions: Aortic root replacement using Freestyle bioprostheses is a viable option for patients with severe aortic stenosis with low risk of hospital readmission for heart failure. (J Thorac Cardiovasc Surg 2019;158:1021-7)

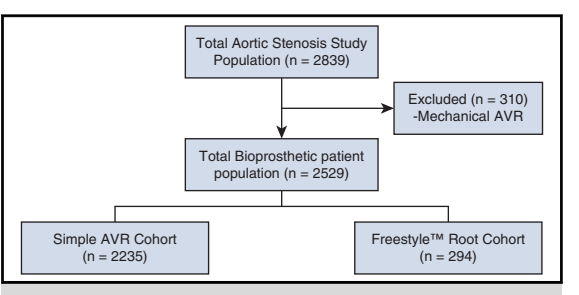

Consort-like diagram illustrating patients with aortic stenosis managed with surgery.

\section{Central Message}

Complete aortic root replacement with Freestyle prosthesis in aortic stenosis populations can be performed safely and effectively.

\section{Perspective}

Aortic root replacement with the Freestyle bioprosthesis offers a favorable hemodynamic profile similar to a native valve and can be performed in patients with aortic stenosis with acceptable operative mortality and low readmission rates for heart failure with low transvalvular gradients over time on follow-up.

See Commentaries on pages 1028 and 1030 .
Stented aortic prostheses have long been considered the primary surgical option for aortic valve replacement (AVR) until the advent of stentless prostheses in the 1990s, which have been widely adopted as legitimate valve-replacement options for aortic pathology. ${ }^{1-8}$ Stentless porcine aortic valves such as Freestyle (Medtronic, Inc, Minneapolis, Minn) aortic xenografts are now in widespread use with

\footnotetext{
From the ${ }^{a}$ Division of Cardiac Surgery, Department of Cardiothoracic Surgery, University of Pittsburgh, Pittsburgh; and ${ }^{\mathrm{b}} \mathrm{Heart}$ and Vascular Institute, University of Pittsburgh Medical Center, Pittsburgh, Pa.

Received for publication July 22, 2018; revisions received Oct 24, 2018; accepted for publication Nov 4, 2018; available ahead of print Jan 8, 2019.

Address for reprints: Ibrahim Sultan, MD, Division of Cardiac Surgery, 5200 Centre Ave, Suite 715, Pittsburgh, PA 15232 (E-mail: sultani@upmc.edu). $0022-5223 / \$ 36.00$

Copyright (c) 2018 by The American Association for Thoracic Surgery https://doi.org/10.1016/j.jtcvs.2018.11.028
}

the known advantages of favorable hemodynamic properties similar to the native valve, low thrombogenicity, and acceptable durability. ${ }^{8-10}$ Stentless aortic valves have been shown to offer reduced postoperative transvalvular gradients and significantly reduced patient-prosthesis mismatch (PPM) compared with stented AVR. ${ }^{11}$ Furthermore, stentless AVRs lead to improved postoperative left ventricular mass regression, suggesting increased efficacy in the setting of aortic stenosis with heart failure. ${ }^{12,13}$ Multiple reports have been published demonstrating favorable outcomes for the use of the Freestyle aortic bioprosthesis for root replacement. $^{9,14-19}$ There is, however, a dearth of literature reporting outcomes for root replacement with Freestyle aortic prostheses in populations that consist of a majority of patients with severe aortic stenosis. The aim 


\section{Abbreviations and Acronyms \\ $\mathrm{AVR}=$ aortic valve replacement \\ $\mathrm{CABG}=$ coronary artery bypass grafting \\ $\mathrm{CHF}=$ congestive heart failure \\ COPD $=$ chronic obstructive pulmonary disease \\ EOA $=$ effective orifice area \\ $\mathrm{HR}=$ hazard ratio \\ NYHA $=$ New York Heart Association \\ PPM = patient-prosthesis mismatch \\ TAVR $=$ transcatheter aortic valve replacement}

of this study was to evaluate our outcomes for Freestyle aortic root replacements in patients who have aortic stenosis, with particular focus on operative and midterm mortality and freedom from readmission for heart failure.

\section{METHODS \\ Study Population}

This study included all patients undergoing aortic root replacement using the Freestyle prosthesis with a primary diagnosis of aortic stenosis from 2011 to 2017. Patients were chosen for Freestyle root based on preoperative assessment indicating high potential for PPM. Factors such as large body surface area along with intraoperative confirmation of small annular dimensions supported the decision of stentless aortic root replacement. Patients who desired a mechanical valve underwent an annular enlargement with a mechanical root replacement and were not included in this study. Subcoronary stentless valve replacement and aortic valve-only procedures were excluded. Data from these patients were retrospectively extracted from a prospectively maintained cardiac surgical database. The institutional review board approved use and analysis of the database.

\section{Surgical Strategy}

Freestyle aortic root replacement was performed via median sternotomy. After preparation of the aortic root after debridement of the annulus, the Freestyle sizer was used to size the annulus in an intra-annular fashion. ${ }^{20}$ The conduit was then sewn to the annulus using running or interrupted 3-0 polypropylene. ${ }^{21}$ Retrograde and anterograde cardioplegia were use throughout the operation. Both coronary ostia were reimplanted in an orthotopic fashion using running 5-0 polypropylene. The distal aortic anastomosis was then performed using running 4-0 propylene.

\section{Statistical Analysis}

Primary outcomes included short-term and mid-term survival and incidence of reoperative aortic surgery. Secondary outcomes included immediate postoperative complications and freedom from heart failure readmission. All-cause mortality was obtained from the review of the medical record death summary for patients who died during index hospitalization or readmissions, phone calls when appropriate, and through the Social Security Death Index (obtained from the updated Social Security Administration Death Master file, where our health care system is certified by the Social Security Administration as an organization that is exempt from the 3-year delay). Descriptive statistics are presented as means \pm standard deviation for continuous and parametric variables, and percentage (frequency) for categorical variables. Mean and median follow-up were calculated based on documented dates of last clinic visit. A Kaplan-Meier time to event plot was created to draw survival curves and calculate 1- and 5-year survival rates. Univariate analysis was performed to identify significant associations with 30-day, 1 year, and 5- year survival. For variables for which univariate analysis resulted in a level of significance determined by $P<.2$, multivariable analysis was performed. ${ }^{22}$ Multivariable proportional hazard Cox regression model was used with censoring follow-up at the different landmark times. Proportional hazard assumption was tested using methodology developed by Grambsch and Therneau, ${ }^{23}$ and the proportional hazard was met in each model. In the 30-day model, the $P$ value was .92 , at 1 year the $P$ value was .99 , and at 5 years, the $P$ value was .90 .

\section{RESULTS \\ Baseline Characteristics}

In total, 2529 patients with severe AS who needed an open aortic valve replacement with a biological prosthesis were operated on between 2011 and 2017. Of these, 294 patients underwent aortic root replacement for aortic stenosis using Freestyle prosthesis. During the same time period, a total of 701 patients underwent aortic root surgery. The cohort was majority white $(93.2 \%)$ and male $(53.7 \%)$ with a mean age of $67.5 \pm 13.0$ years. Multiple preoperative characteristics were reported in Table 1, including, but not limited to, preoperative ejection fraction of $54.8 \pm 10.8$, diabetes $(26.2 \%)$, hypertension $(85.7 \%)$, severe chronic obstructive pulmonary disease (COPD; $4.8 \%$ ), dialysis dependence $(0.7 \%)$, endocarditis $(8.2 \%)$, cerebrovascular accident history $(11.2 \%)$, previous cardiac surgery $(28.6 \%)$, history of heart failure $(34.4 \%)$, and heart failure within 2 weeks of admission for aortic root replacement 102 $(34.7 \%)$. One hundred twelve $(38.1 \%)$ patients had baseline coronary artery disease. The mean aortic valve gradient was $43.6 \pm 19.9 \mathrm{~mm} \mathrm{Hg}$. Severe aortic regurgitation was present in $88(29.9 \%)$ patients, and $20(6.8 \%)$ patients had severe mitral regurgitation. A total of $12(4.1 \%)$ patients had severe tricuspid valve regurgitation.

\section{Operative Characteristics}

Procedural characteristics are presented in Table 2. Mean Society of Thoracic Surgeons Predicted Risk of Mortality when calculated with the assumption of AVR \pm coronary artery bypass grafting $(\mathrm{CABG})$ was $8.10 \% \pm 10.8$, reflecting a high-risk cohort. Eighty-four (28.6\%) patients underwent reoperative sternotomies. One hundred twelve $(38.1 \%)$ operations were performed with urgent or emergent status. The mean total cardiopulmonary bypass time was $198 \pm 78.4$ minutes and mean crossclamp time was $155 \pm 58.8$ minutes. The mean cardiopulmonary bypass and crossclamp times for isolated Freestyle root replacements were $163.8 \pm 61.0$ minutes and $127.0 \pm 45.0$ minutes, respectively. The majority of patients $(88.4 \%)$ had both anterograde and retrograde cardioplegia. A total of 104 (35.4\%) patients had concomitant CABG, 64 $(21.8 \%)$ patients had reoperative aortic valve/root replacement, $75(25.5 \%)$ had ascending aortic replacement, 36 $(12.2 \%)$ concomitant mitral surgery, and $6(2.0 \%)$ patients had concomitant tricuspid surgery. 
TABLE 1. Baseline characteristics undergoing Freestyle aortic root replacement for aortic stenosis

\begin{tabular}{|c|c|}
\hline Characteristics & $\mathbf{N}=\mathbf{2 9 4}$ \\
\hline Age, y & $67.5 \pm 13.0$ \\
\hline Male & $158(53.7 \%)$ \\
\hline BMI & $29.7 \pm 6.62$ \\
\hline Diabetes mellitus & $77(26.2 \%)$ \\
\hline Hypertension & $252(85.7 \%)$ \\
\hline Severe COPD & $14(4.8 \%)$ \\
\hline Renal failure on dialysis & $2(0.7 \%)$ \\
\hline Infective endocarditis & $24(8.2 \%)$ \\
\hline Immunosuppressive medication therapy & $19(6.5 \%)$ \\
\hline History of mediastinal radiation & $5(1.7 \%)$ \\
\hline History of peripheral arterial disease & $85(28.9 \%)$ \\
\hline Syncope within $1 \mathrm{y}$ & $19(6.5 \%)$ \\
\hline History of CVD & $78(26.5 \%)$ \\
\hline History of CVA & $33(11.2 \%)$ \\
\hline Previous cardiac surgery & $84(28.6 \%)$ \\
\hline Previous PCI & $33(11.2 \%)$ \\
\hline Previous MI & $59(20.1 \%)$ \\
\hline History of heart failure & $101(34.4 \%)$ \\
\hline Heart failure within $2 \mathrm{wk}$ & $102(34.7 \%)$ \\
\hline Creatinine & $1.14 \pm 0.63$ \\
\hline Total albumin & $3.66 \pm 0.55$ \\
\hline $\mathrm{HDEF}$ & $54.8 \pm 10.8$ \\
\hline Aortic valve mean gradient, $\mathrm{mm} \mathrm{Hg}$ & $43.6 \pm 19.9$ \\
\hline Aortic valve area, $\mathrm{cm}^{2}$ & $0.85 \pm 0.44$ \\
\hline Severe aortic regurgitation & $88(29.9 \%)$ \\
\hline Severe mitral regurgitation & $20(6.8 \%)$ \\
\hline Severe tricuspid regurgitation & $12(4.1 \%)$ \\
\hline
\end{tabular}

\section{Postoperative Morbidity and Mortality}

Postoperative complications are presented in Table 3. The postoperative (30-day) mortality was $7.1 \%$. The postoperative 30-day mortality for isolated Freestyle root replacement was $4.4 \%$. Mortality at 1 and 5 years was $13.9 \%$ and $23.7 \%$, respectively. One hundred sixty $(54.4 \%)$ patients received blood products in the postoperative period. Twenty-two $(7.5 \%)$ patients had to return to the operating room for mediastinal bleeding. Ten $(3.4 \%)$ patients had a stroke. Twenty $(6.8 \%)$ patients had renal failure and required dialysis postoperatively. Twenty-nine $(9.9 \%)$ patients had new pacemaker placement, and $120(40.8 \%)$ patients developed new postoperative atrial fibrillation. The median follow-up time for the entire group was 2.7 years (interquartile range 0.9-4.5). A total of 55 patients had follow-up for $\geq 5$ years. During this time period, 2
TABLE 2. Operative characteristics for patients undergoing Freestyle aortic root replacement for aortic stenosis

\begin{tabular}{lc}
\hline \multicolumn{1}{c}{ Characteristics } & N $=\mathbf{2 9 4}$ \\
\hline STS PROM (\%) & $8.10 \pm 10.8$ \\
Reoperative sternotomy & $84(28.6 \%)$ \\
\hline Urgent & $76(25.9 \%)$ \\
Emergent & $36(12.2 \%)$ \\
\hline CPB, min & $198 \pm 78.4$ \\
XC, min & $155 \pm 58.8$ \\
\hline Isolated freestyle root replacement CPB time, min & $163.8 \pm 61.0$ \\
Isolated freestyle root replacement XC time, min & $127.0 \pm 45.0$ \\
\hline IABP postsurgery & $14(4.8 \%)$ \\
Cardioplegia delivery & \\
Antegrade only & $12(4.1 \%)$ \\
Retrograde only & $22(7.5 \%)$ \\
Both & $260(88.4 \%)$ \\
\hline Concomitant procedures & \\
CABG & $104(35.4 \%)$ \\
Reoperative aortic valve & $52(17.7 \%)$ \\
Reoperative aortic root & $12(4.1 \%)$ \\
Mitral surgery & $36(12.2 \%)$ \\
Tricuspid surgery & $6(2.0 \%)$ \\
Ascending aortic replacement & $75(25.5 \%)$ \\
\hline STS $P R O M$, Socis of & \\
\hline
\end{tabular}

STS PROM, Society of Thoracic Surgeons Predicted Risk of Mortality; CPB, cardiopulmonary bypass time; $X C$, crossclamp time; $I A B P$, intra-aortic balloon pump; $C A B G$, coronary artery bypass grafting.

patients had aortic root reoperations for endocarditis. Kaplan-Meier mortality estimates (Figure 1) at 1 and 5 years for the entire cohort were $16.6 \%$ and $27.6 \%$, respectively. However, for isolated Freestyle replacement, 1 - and 5-year mortality estimates were $13.9 \%$ and $23.7 \%$ respectively.

\section{Hospital Readmissions}

Over the follow-up period, a total of $40(13.6 \%)$ patients had congestive heart failure (CHF)-related readmissions. Readmissions for $\mathrm{CHF}$ at 30 days, 1 year, and 5 years were $5.6 \%, 11.8 \%$, and $17.4 \%$, respectively. All cause readmission at 30 days, 1 year, and 5 years was $13.2 \%$, $26.1 \%$, and $39.7 \%$, respectively.

\section{Valve and Echocardiographic Findings}

Immediate postoperative, 30-day, and 1-year follow-up transvalvular mean gradients were measured via echocardiography and were reported as $9.32,7.15$, and $6.32 \mathrm{~mm} \mathrm{Hg}$, respectively (Table 4). Mean valve size used was $25.4 \pm 2.58$. Effective orifice area (EOA) index for each patient was calculated using EOA provided by manufacturer charts for specific valve size divided by body surface area. The mean EOA was then calculated and was found to be $1.11 \pm 0.20$. 
TABLE 3. Postoperative complications of patients undergoing Freestyle aortic root replacement for aortic stenosis

\begin{tabular}{lc}
\hline \multicolumn{1}{c}{ Characteristics } & $\mathbf{N}=\mathbf{2 9 4}$ \\
\hline Operative (30-d) mortality & $21(7.1 \%)$ \\
Stroke & $10(3.4 \%)$ \\
Deep sternal wound infection & $1(0.3 \%)$ \\
Re-exploration for mediastinal bleeding & $22(7.5 \%)$ \\
\hline Postoperative sepsis & $11(3.7 \%)$ \\
Pulmonary ventilation $>24 \mathrm{~h}$ & $77(26.2 \%)$ \\
Pneumonia & $33(11.2 \%)$ \\
Renal failure requiring dialysis & $20(6.8 \%)$ \\
New-onset atrial fibrillation & $120(40.8 \%)$ \\
New pacemaker & $29(9.9 \%)$ \\
Blood products transfused & $160(54.4 \%)$ \\
\hline
\end{tabular}

\section{Multivariable Analysis}

Multivariable analysis (Table 5) was reported for significant associations with 30-day, 1-year, and 5-year mortality. All univariate variables with $P<.20$ were included in the multivariable models. There were no baseline characteristics on multivariable analysis that were associated with 30-day mortality. Multivariable analysis for variables associated with 1-year mortality yielded significant associations for age (hazard ratio [HR] 1.04 [1.01-1.07]; $P=.001$ ), female sex (HR 1.79 [1.07-3.02]; $P=.027$ ), heart failure within 2 weeks (HR $1.64(1.00-2.68) ; P=.048)$, and severe COPD (HR 5.10 [2.23-11.7]; $P=.000$ ). Similarly, significant associates for multivariable analysis for 5-year mortality include age (HR 1.04 [1.02-1.07]; $P \leq .001$ ), female sex (HR 1.77 [1.06-2.96]; $P=.030$ ), heart failure within 2 weeks (HR 1.63 [0.99-2.67]; $P=.054$ ), and severe COPD (HR 4.59 [2.00-10.6]; $P \leq .001$ ). Heart failure within 2 weeks of aortic root replacement was the only factor associated with both 30-day (HR 3.97 [1.35-11.67]; $P=.012$ ) and 1-year (HR 2.53 [1.20-5.36]; $P=.015$ ) CHF hospitalizations on multivariable analysis. There was a negative association between mortality at 1 year and presence of aortic root aneurysm (HR 0.40 [0.17-0.95]; $P=.037$ ). Female sex (HR 2.02 [0.98-4.16]; $P=.058$ ), age (HR 1.03 [1.00-1.07]; $P=.040$ ), and heart failure within 2 weeks of root replacement (HR 2.68 [1.39-5.16]; $P=.003$ ) were significant predictors of readmission for $\mathrm{CHF}$ within 5 years.

\section{DISCUSSION}

In an effort to accommodate sufficiently large aortic valves and maintain low postoperative transvalvular gradients, the full root technique has been reported as the primary method of choice for stentless aortic root bioprosthesis. ${ }^{19}$ Aortic root replacement with stentless conduits such as the Freestyle prosthesis have been in use for nearly 2 decades with acceptable results. The distinct hemodynamic

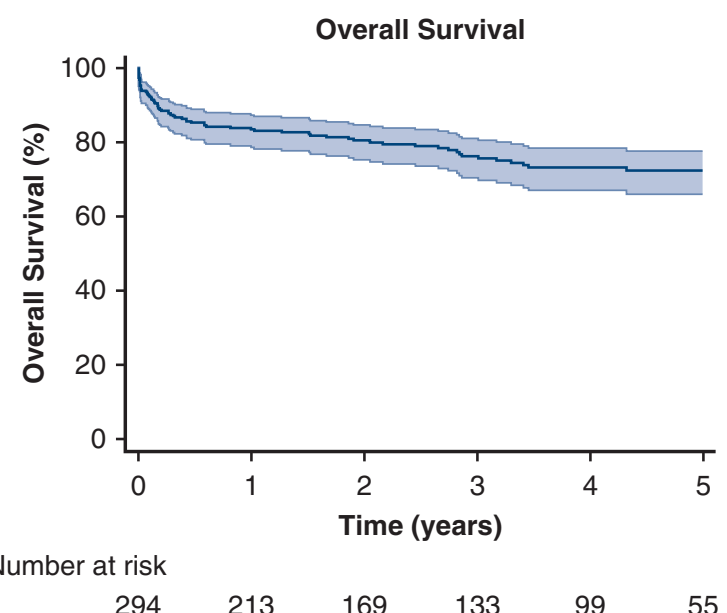

FIGURE 1. Freedom from mortality after Freestyle aortic root replacement for aortic stenosis.

performance similar to the native valve, ${ }^{24}$ including low transvalvular gradients and improved EOA have made stentless prostheses an attractive option. ${ }^{25}$ Interestingly, the trend of postoperative mean gradient reduction overtime has been upheld even in patients with smaller valve sizes $(<23 \mathrm{~mm})$, and gradients can remain $\leq 8 \mathrm{~mm} \mathrm{Hg}$ in patients with 21 -mm valves. ${ }^{25}$ The low transvalvular gradients at 1 year in our series indicate the same.

In an attempt to create the most favorable anatomic conditions with hemodynamics similar to the native valve, it is our practice to implant stentless aortic xenografts using complete root replacements in patients with small aortic roots with concomitant aortic stenosis. By adopting this method, we have attempted to allow patients to have appropriate LV unloading in a patient population prone to high transvalvular gradients and increased LV stroke work. The relevance of this approach is underscored by evidence that PPM and its relation to low left ventricular ejection fraction is an independent predictor of short-term postoperative mortality following AVR. ${ }^{26}$ The efficacy of full root replacement with stentless xenografts is supported by our low rate of postoperative heart failure readmissions with Kaplan-Meier estimates of $82.6 \%$ freedom from CHF hospitalizations at 5 years.

Despite these advantages, the full root method for Freestyle aortic root replacement comes with its drawbacks, including an inherently more challenging surgical technique with the need for reimplantation of coronary buttons, multiple suture lines, potentially increased bleeding and cardiopulmonary bypass times, and calcification of the bio-root over time. Furthermore, as demonstrated by our patient population, with a high percentage of patients with small aortic annuli, reoperative aortic valve and root procedure, and concomitant valve procedures, there is the potential for increased postoperative pacemaker $(9.9 \%)$ 
TABLE 4. Echocardiography, valve size, and EOAi for patients undergoing Freestyle root replacement for aortic stenosis

\begin{tabular}{lcccc}
\hline \multicolumn{1}{c}{ Variable } & Preoperative & Intraoperative & One-month postoperative & One-year postoperative \\
\hline Mean gradient, $\mathrm{mm} \mathrm{Hg}$ & $43.6 \pm 19.9$ & $43.6 \pm 19.9$ & $7.15 \pm 4.47$ & $6.32 \pm 4.76$ \\
Mean valve size & $\mathrm{n} / \mathrm{a}$ & $25.4 \pm 2.58$ & $\mathrm{n} / \mathrm{a}$ & $\mathrm{n} / \mathrm{a}$ \\
EOAi & $\mathrm{n} / \mathrm{a}$ & $1.11 \pm 0.20$ & $\mathrm{n} / \mathrm{a}$ & $\mathrm{n} / \mathrm{a}$ \\
\hline
\end{tabular}

$n / a$, Not available; $E O A i$, effective orifice area index.

requirements. Given these challenges, there is a clear learning curve associated with full root replacement with bioprosthetic conduits, and routine use of this procedure should be limited to surgeons who are well versed in this technique.

However, this has not limited the potential for safe and effective use of this method, as demonstrated by numerous series. ${ }^{9,14-19}$ Lemaire and colleagues ${ }^{14}$ reported early and late outcomes for 132 patients with aneurysmal disease involving the aortic root who underwent root replacement with stentless porcine xenografts $(59 \%$ Toronto Bio-root; $41 \%$ Freestyle). The majority of patients had either severe $(56.8 \%)$ or moderate $(22.7 \%)$ aortic regurgitation with only $9(6.8 \%)$ patients having severe aortic stenosis. Operative mortality was $7.6 \%$ and survival for Freestyle bio-root at 1 year and 5 years was $79.6 \%$ and $74.1 \%$, respectively. Of note, survivors had significant reduction in New York Heart Association (NYHA) status and improved left ventricular ejection fraction.

Previous large series for patients who underwent full bioroot replacement for variable aortic pathology reported operative mortality from $3.6 \%$ to $7.6 \%$ and the need for reoperations ranging from $4.7 \%$ to $17.4 \%$. ${ }^{5,7,8,14,18,27,28}$ Most of the contemporary literature focuses on the durability for stentless root replacement outcomes in patients with aneurysmal disease. In the current study, we present a patient population that is unique in that they are a highrisk cohort with severe aortic stenosis. Our patient cohort, consisting of a large series $(n=294)$ composed primarily of patients with severe aortic stenosis, had comparable operative mortality at $7.1 \%$. Of note, the operative mortality in our series is significantly greater than what would be expected for simple isolated AVR, but our patient population had a mean Society of Thoracic Surgeons Predicted Risk of Mortality of $8.10 \% \pm 10.8 .^{29}$ This clearly reflects a high-risk group of patients as a consequence of multiple comorbidities and concomitant procedures. Interesting, on multivariable analysis there was a negative association between mortality at 1 year and presence of aortic root aneurysm (HR 0.40 [0.17-0.95]; $P=.037$ ). Therefore, on risk-adjusted survival at 1 year, aortic root dilation from pre-existing aneurysmal disease may be protective. ${ }^{30-32}$ However, there is an unclear association between root dilatation and improved survival, and this may be due to an easier technical operation.

Reduced EOA and small aortic roots can be challenging obstacles to overcome when performing aortic valve/root procedures, especially in populations consisting largely of patients with severe AS with mean baseline preoperative gradients $>40 \mathrm{~mm} \mathrm{Hg}$. In the current transcatheter aortic valve replacement (TAVR) era, one may speculate on the potential advantage of TAVR with presumed lower risk of PPM in this patient population. However, recent data from the Society of Thoracic Surgeons Transcatheter Valve Therapy registry ${ }^{33}$ reported moderate or severe PPM in $37 \%$ of the TAVR patient population, and these patients had increased mortality and hospital readmissions for heart failure at 1 year. Given that nearly $21 \%$ of our cohort had a previous aortic valve or aortic root replacement, we would have expected a significant degree of PPM in these patients if

TABLE 5. Multivariable model: association between baseline characteristics and mortality

\begin{tabular}{|c|c|c|c|c|c|c|}
\hline \multirow[b]{2}{*}{ Variable } & \multicolumn{2}{|l|}{ Thirty-day } & \multicolumn{2}{|l|}{ One-year } & \multicolumn{2}{|l|}{ Five-year } \\
\hline & Hazard ratio $(95 \%$ CI $)$ & $P$ value & Hazard ratio $(95 \%$ CI $)$ & $P$ value & Hazard ratio $(95 \%$ CI $)$ & $P$ value \\
\hline Age & $1.03(0.99-1.08)$ & .154 & 1.04 (1.01-1.07) & .001 & $1.04(1.02-1.07)$ & .000 \\
\hline Female vs male & $2.03(0.78-5.27)$ & .145 & $1.79(1.07-3.02)$ & .027 & $1.77(1.06-2.96)$ & .030 \\
\hline Hypertension & NS & NS & $0.81(0.63-1.03)$ & .086 & $0.81(0.63-1.05)$ & .117 \\
\hline Heart failure within $2 \mathrm{wk}$ & $1.27(0.52-3.11)$ & .597 & $1.64(1.00-2.68)$ & .048 & $1.63(0.99-2.67)$ & .054 \\
\hline Previous stroke & NS & NS & $1.25(0.67-2.35)$ & .478 & $2.29(1.25-4.2)$ & .008 \\
\hline \multicolumn{7}{|l|}{ Chronic lung disease } \\
\hline Mild & $1.64(0.52-5.24)$ & .399 & $1.00(0.49-2.03)$ & .996 & $0.98(0.48-1.99)$ & .970 \\
\hline Moderate & $1.42(0.312-6.47)$ & .648 & $1.52(0.70-3.30)$ & .288 & $1.47(0.68-3.19)$ & .324 \\
\hline Severe & $3.13(0.66-14.9)$ & .150 & $5.10(2.23-11.7)$ & .000 & $4.59(2.00-10.6)$ & .001 \\
\hline
\end{tabular}

$C I$, Confidence interval; $N S$, not significant on univariable analysis. 
they were to undergo valve-in-valve TAVR. Our cohort consisted of patients with a mean preoperative transvalvular gradient of $43.6 \mathrm{~mm} \mathrm{Hg}$ and greater than one third of patients had NYHA III or NYHA IV heart failure within 2 weeks of admission for aortic root replacement.

Stentless bioprosthetic roots have been shown to have favorable hemodynamics in the setting of small aortic annuli and heavily calcified aortic valves. ${ }^{34,35}$ Although a technically challenging procedure with potential increased morbidity, the advantages of full root replacement should be emphasized over the subcoronary implantation technique, which has been shown to have questionable longevity with increased sinotubular junction dilation and aortic regurgitation on long-term follow-up. ${ }^{36}$

\section{Limitations}

This study has limitations inherent to retrospective study design. In addition, postoperative echocardiography results were not reported in all patients, which limited the assessment of some hemodynamic parameters. This study is also limited by only recording follow-up to a length of 5 years, although longer term outcomes at 10 and 15 years are relevant to the discussion of the development of heart failure, $\mathrm{LV}$ mass regression, and EOA.

\section{CONCLUSIONS}

Aortic root replacement using Freestyle bioprostheses with the full root technique is a viable option for patients with severe aortic stenosis. Early and midterm mortality and need for reoperations in this patient population is commensurate with other contemporary series performing root replacement with porcine xenografts. Root replacement with stentless aortic xenografts is particularly advantageous for a subset of patients with small aortic roots who are at risk for patient prosthesis mismatch.

\section{Conflict of Interest Statement}

Authors have nothing to disclose with regard to commercial support.

\section{References}

1. Akar AR, Szafranek A, Alexiou C, Janas R, Jasinski MJ, Swanevelder J, et al Use of stentless xenografts in the aortic position: determinants of early and late outcome. Ann Thorac Surg. 2002;74:1450-7.

2. Bach DS, Metras J, Doty JR, Yun KL, Dumesnil JG, Kon ND. Freedom from structural valve deterioration among patients aged $\leq 60$ years undergoing Freestyle stentless aortic valve replacement. J Heart Valve Dis. 2007;16:649-56.

3. Doty DB, Cafferty A, Cartier P, Huysmans HA, Kon ND, Krause AH, et al. Aortic valve replacement with Medtronic Freestyle bioprosthesis: 5-year results. Semin Thorac Cardiovasc Surg. 1999;11:35-41.

4. Kappetein AP, Braun J, Baur LH, Prat A, Peels K, Hazekamp MG, et al. Outcome and follow-up of aortic valve replacement with the Freestyle stentless bioprosthesis. Ann Thorac Surg. 2001;71:601-7.

5. Melina G, De Robertis F, Gaer JA, Amrani M, Khaghani A, Yacoub MH. Midterm pattern of survival, hemodynamic performance and rate of complications after Medtronic Freestyle versus homograft full aortic root replacement: results from a prospective randomized trial. J Heart Valve Dis. 2004;13:972-5.
6. Bach DS, Cartier PC, Kon ND, Johnson KG, Deeb GM, Doty DB. Impact of implant technique following Freestyle stentless aortic valve replacement. Ann Thorac Surg. 2002;74:1107-13.

7. David TE, Mohr FW, Bavaria JE, Hammon JW Jr, Smith MJ III, Rd Quinn, et al. Initial experience with the Toronto root bioprosthesis. J Heart Valve Dis. 2004; 13:248-51.

8. Kon ND, Cordell AR, Adair SM, Kitzman DW. Comparison of results using freestyle stentless porcine aortic root bioprosthesis with the cryopreserved aortic allograft. Semin Thorac Cardiovasc Surg. 1999;11:69-73.

9. Kon ND, Riley RD, Adair SM, Kitzman DW, Cordell AR. Eight-year results of aortic root replacement with the "freestyle" stentless porcine aortic root bioprosthesis. Ann Thorac Surg. 2002;73:1817-21.

10. Yun KL, Jamieson WR, Khonsari S, Burr LH, Munro AI, Sintek CF. Prosthesispatient mismatch: hemodynamic comparison of stented and stentless aortic valves. Semim Thorac Cardiovasc Surg. 1999;11:98-102.

11. Wollersheim LW, Li WW, Kaya A, Bouma BJ, Driessen AH, van Boven WJ, et al. Stentless vs stented aortic valve bioprosthesis in the small aortic root. Semin Thorac Cardiovasc Surg. 2016;28:390-7.

12. Kunadian B, Vijayalakshmi K, Thornley AR, de Belder MA, Hunter S, Kendall S, et al. Meta-analysis of valve hemodynamics and left ventricular mass regression for stentless versus stented aortic valves. Ann Thorac Surg. 2007;84:73-8.

13. Maselli D, Pizio R, Bruno LP, Di Bella I, De Gasperis C. Left ventricular mass reduction after aortic valve replacement: homografts, stentless and stented valves. Ann Thorac Surg. 1999;67:966-71.

14. Lemaire SA, Gree SY, Sharma K, Cheung CK, Sameri A, Tsai PL, et al. Aortic root replacement with stentless porcine xenografts: early and late outcomes in 132 patients. Ann Thorac Surg. 2009;87:503-12.

15. Mazzola A, Di Mauro M, Pellone F, Faragalli F, Villani C, DiEusanio M, et al. Freestyle aortic root bioprosthesis is a suitable alternative for aortic root replacement in elderly patients: a propensity score study. Ann Thorac Surg. 2012;94:1185-90.

16. Bach DS, Kon ND, Dumesnil JG, Sintek CF, Doty DB. Ten-year outcome after aortic valve replacement with the freestyle stentless bioprosthesis. Ann Thorac Surg. 2005;80:480-6.

17. Bach DS, Kon ND. Long-term clinical outcomes 15 years after aortic valve replacement with the Freestyle stentless aortic bioprosthesis. Ann Thorac Surg. 2014;97:544-51.

18. Schneider AW, Putter H, Hazekamp MG, Holman ER, Bruggemans EF, Versteegh MIM, et al. Twenty-year experience with stentless biological aortic valve and root replacement: informing patients of risks and benefits. Eur J Cardiothorac Surg. 2018;53:1272-8.

19. Dapunt OE, Easo J, Phillip PF, Murin P, Sudkamp M, Horst M, et al. Stentless full root bioprosthesis in surgery for complex aortic valve-ascending aortic disease: a single center experience of over 300 patients. Eur J Cardiothorac Surg. 2008;33:554-9.

20. Sultan I, Komlo CM, Bavaria JE. How I teach a valve-sparing root replacement. Ann Thorac Surg. 2016;101:422-5.

21. Sultan I, Seese L, Lagazzi L, Gleason TG. Concomitant aortic valve replacement with orthotopic heart transplantation. J Thorac Cardiovasc Surg. 2018;155: e151-2.

22. Bursac Z, Gauss CH, Williams DK, Hosmer DW. Purposeful selection of variables in logistic regression. Source Code Biol Med. 2008;3:17.

23. Grambsch PM, Therneau TM. Proportional hazard tests and diagnostics based on weighted residuals. Biometrika. 1994;81:515-26.

24. Matsue H, Sawa Y, Toshiki T, Matsuemiya G, Ohtake S, Hamada S, et al. Threedimensional flow velocity quantification of Freestyle aortic stentless bioprosthesis by magnetic resonance imaging: surgical consideration. Semin Thorac Cardiovasc Surg. 2001;13:60-6.

25. Baur LHB, Jin XY, Houdas Y, Peels CH, Braun J, Kappetein AP, et al. Echocardiographic parameters of the freestyle stentless bioprosthesis in aortic position: the European experience. J Am Soc Echocardiogr. 1999;12:729-35.

26. Blais C, Dumesnil JG, Baillot R, Simard S, Doyle D, Pibarot P. Impact of valve prosthesis-patient mismatch on short-term mortality after aortic valve replacement. Circulation. 2003;108:983-8.

27. Gleason TG, David TE, Coselli JS, Hammon JW Jr, Bavaria JE, et al. St. Jude Medical Toronto biologic aortic root prosthesis: early FDA phase II IDE study results. Ann Thorac Surg. 2004;78:786-93.

28. Kincaid EH, Cordell AR, Hammon JW, Adair SM, Kon ND. Coronary insufficiency after stentless aortic root replacement: risk factors and solutions. Ann Thorac Surg. 2007;83:964-8.

29. Kilic A, Bianco V, Gleason TG, Aranda-Michel E, Chu D, Navid F, et al. Hospital readmission rates are similar between patients with mechanical versus bioprosthetic aortic valves. J Card Surg. 2018;33:497-505. 
30. Sultan I, Bianco V, Yajzi I, Kilic A, Dufendach K, Cardounel A, et al. Hemiarch reconstruction vs clamped aortic anastomosis for concomitant ascending aortic aneurysm. Ann Thorac Surg. 2018;106:750-6.

31. Kilic A, Arnaoutakis GJ, Bavaria JE, Sultan I, Desai NG, Vallabhajosyula P, et al. Outcomes of elective aortic hemiarch reconstruction for aneurysmal disease in the elderly. Ann Thorac Surg. 2017;104:1522-30.

32. Arnaoutakis GJ, Vallabhajosyula P, Bavaria JE, Sultan I, Siki M, Naidu S, et al. The impact of deep versus moderate hypothermia on postoperative kidney function after elective aortic hemiarch repair. Ann Thorac Surg. 2016;102:1313-21.

33. Herrmann HC, Daneshvar SA, Fonarow GC, Stebbins A, Vemulapalli S, Desai ND, et al. Prosthesis-patient mismatch in 62,125 patients following transcatheter aortic valve replacement: from the STS/ACC TVT registry. J Am Coll Cardiol. 2018;72:2701-11.
34. Kunihara T, Schmidt K, Glombitza P, Dzindzibadze V, Lausberg H, Schafers HJ Root replacement using stentless valves in the small aortic root: a propensity score analysis. Ann Thorac Surg. 2006;82:1379-84.

35. Baur LH, Houdas Y, Peels KH, Braun J, van Straten B, Prat A, et al. Stentless bioprostheses have ideal haemodynamics, even in the small aortic root. Int $J$ Card Imaging. 2000;16:359-64.

36. David TE, Ivanov J, Eriksson MJ, Bos J, Feindel CM, Rakowski H. Dilation of the sinotubular junction causes aortic insufficiency after aortic valve replacement with the Toronto SPV bioprosthesis. Thorac Cardiovasc Surg. 2001;122:929-34.

Key Words: aortic root replacement, valve surgery, aortic stenosis, Freestyle aortic root, porcine xenograft

Readers who found these articles interesting may also like to read the following papers found in recent and future issues of our sister publications, Seminars in Thoracic and Cardiovascular Surgery and Operative Techniques in Thoracic and Cardiovascular Surgery!

\section{Adult: Aortic Valve}

Axillary Transcatheter Aortic Valve Replacement in Patients With Peripheral Vascular Disease. Hysi I, Gommeaux A, Pécheux M, et al. Semin Thorac Cardiovasc Surg. 2019 Summer;31(2):175-180.

Commentary: Alternative TAVR Access: Is It Time to Alter Your Alternative Access Strategy? McKiernan M, Lisko J, Grubb KJ. Semin Thorac Cardiovasc Surg. 2019 Summer;31(2):181-182.

Root Reimplantation With Leaflet Repair. Svensson LG. Semin Thorac Cardiovasc Surg. 2019 Summer;31(2):153-154.

Commentary: Words of Wisdom on Valve-Sparing Aortic Root Reimplantation When Leaflet Repair Is Necessary. Girardi LN. Semin Thorac Cardiovasc Surg. 2019 Summer;31(2):155-156.

Aortic Root Remodeling. Schneider U, Schäfers H-J. Oper Tech Thorac Cardiovasc Surg. In press. Published online 03-28-19. 